\title{
A Dimensão Estética na Aprendizagem: desocultando pontos cegos
}

\begin{abstract}
Ana Beatriz Machado de Freitas'
'Pontifícia Universidade Católica de Goiás (PUC Goiás), Goiânia/GO - Brasil

RESUMO - A Dimensão Estética na Aprendizagem: desocultando pontos cegos. $\mathrm{O}$ artigo versa sobre a dimensão estética na educação, em particular sobre o olhar sensível na aprendizagem. São apresentadas reflexões acerca do ofuscamento, da presença e do resgate desse olhar. Contextualiza-se a configuração da tecnoestética contemporânea, a partir de reflexões de Walter Benjamin; discute-se como ela afeta a percepção e o comportamento dos indivíduos e da coletividade. Comenta-se o impacto desse contexto no desafio de atender às necessidades educacionais de todos no atual cenário da educação inclusiva. Reflete-se, numa leitura psicopedagógica, sobre a importância do saber de experiência para a aprendizagem e sobre o papel do olhar sensível como fundamental mediador. É observado também o compromisso da sociedade com a formação das novas gerações.

Palavras-chave: Aprendizagem. Estética. Experiência. Psicopedagogia. Inclusão.
\end{abstract}

ABSTRACT - The Aesthetic Dimension in The Learning Process: unveiling blind spots. This paper focuses on the aesthetic dimension in education, especially the sensitive view on the learning process. It presents reflections concerning the eclipse, presence and rescue of this view. The contemporary technoaesthetics is put into context, based on Walter Benjamin's reflections; it discusses how it affects the perception and behavior of individuals and the society. It approaches the impact of this context on the challenge to answer to the educational needs of everyone, in the current scenario of inclusive education. Following a psychopedagogical view, it reflects on the importance of the experience-based knowledge for learning and on the sensitive view as a crucial mediator. The engagement of society with the formation of new generations is also observed.

Keywords: Learning. Aesthetic. Experience. Psychopedagogy. Inclusion.

Educação \& Realidade, Porto Alegre, v. 41, n. 2, p. 575-589, abr./jun. 2016. 575 http://dx.doi.org/10.1590/2175-623648223 
A Dimensão Estética na Aprendizagem

O que é um ponto cego? Tecnicamente, é aquilo que o olho não apreende devido à ausência de receptores sensoriais da retina ou devido à determinada posição do observador em relação ao observado ${ }^{1}$. Quanto ao primeiro aspecto, trata-se de uma incompletude perfeitamente normal, fisiologicamente, em nossa espécie; uma deficiência que talvez sinalize nosso limite ou presunção de apreender o real sem que nada nos escape. Na realidade, há sempre o intangível, por mais próximos que estejamos. Na alteridade, por exemplo, está presente o reconhecimento da diferença - portanto, da existência do outro - e a perspectiva de situar-se no lugar deste. No entanto, não podemos ser o outro, e é este limite - justamente o da diferença - que marca o reconhecimento das identidades e do comum. Eis o ponto cego que permite enxergar.

A cegueira propriamente dita tem a ver com a segunda definição do ponto cego, em que a visibilidade tem a ver com o posicionamento do observador em relação ao observado e ao movimento (automover). Conforme o movimento enxerga-se ou não, e com mais ou menos nitidez. Entretanto, talvez pelo conforto ou domesticação àquilo que nos move, nos acomodamos, não mais nos movimentamos para além de automatismos. E isso não diz respeito somente à motricidade física, mas também ao exercício dos sentidos e do intelecto para vislumbrar ângulos, caminhos e velocidades possíveis. Bachelard (1998, p. 19) refere-se, por exemplo, à inércia que domina o espírito científico, quando este cede ao instinto conservativo, em detrimento do formativo: "Chega o momento em que o espírito prefere o que confirma seu saber àquilo que o contradiz, em que gosta mais de respostas do que de perguntas. $\mathrm{O}$ instinto conservativo passa então a dominar, e cessa o crescimento espiritual"2.

Por vezes também nos comportamos, mesmo em contextos triviais, como se estivéssemos em perspectiva de ponto cego. No documentário Janela da Alma (2001), um dos depoentes com deficiência visual, Antônio Cícero, faz o seguinte comentário: "Descobri com óculos que as árvores eram múltiplas e cheias de folhas, e não uma massa”. O relato dessa percepção provoca um abrir de olhos, põe-nos em suspenso quando lembramos de como o desenho costuma ser ensinado nas escolas. Fiquemos com os clássicos: árvore, figura humana e casa. Ensina-se a partir da reprodução de estereótipos ou a partir de produções do olhar sensível? Quem ensina/mostra/faz ver as árvores contidas nas folhas?

Na metáfora do ponto cego encontramos uma sugestiva imagem para reflexões acerca de possibilidades e do papel do olhar sensível na educação, particularmente na compreensão da aprendizagem. O adjetivo sensível, a nosso ver, marca um diferencial de intenção e movimento, contraposto ao olhar massificador que hiperestimula e que é pretensamente onisciente, tal qual o olho Big Brother, característico das sociedades capitalistas contemporâneas.

Discorreremos a respeito da construção/desconstrução do olhar sensível no bojo da sociedade contemporânea e da pertinência de seu resgate para a educação na atualidade. Para tanto, contextualizaremos 576 Educação \& Realidade, Porto Alegre, v. 41, n. 2, p. 575-589, abr./jun. 2016. 
primeiramente o impacto de recentes mudanças sócio-históricas e no âmbito da técnica que alteraram e vêm alterando de forma significativa a percepção humana - objetiva e subjetiva. A seguir, refletiremos acerca de suas repercussões na educação numa leitura psicopedagógica do aprender na relação com o conhecimento e com o saber. Da conjunção dessas reflexões, observamos a possibilidade e os desafios à constituição (ou à recuperação) de uma dimensão estética do aprender pautada no olhar sensível.

\title{
A Tecnoestética na Educação Contemporânea
}

As sociedades capitalistas contemporâneas, também denominadas pós-modernas, caracterizam-se pela instabilidade e pelo efêmero. Instituições, modelos, teorias e recursos a partir dos quais uma geração poderia adotar como parâmetro seguro para autoplanejamento e com previsibilidade já não existem, pois vêm se modificando contínua e aceleradamente. A esse respeito, Haroche (2008, p. 123) toma emprestado de Zygmunt Bauman o adjetivo fluidez para sublinhar que essa característica afeta de forma significativa as relações interpessoais, as sensações - particularmente o olhar humano - e as relações e comportamentos indivíduo-sociedade.

\begin{abstract}
A fluidez descontínua intrinsecamente de limites acarreta modificações nas estruturas e pode pôr em questão a possibilidade de estruturação e mesmo de existência do eu. É possível pensar na fluidez, sob pressão permanente e initerrupta do fluxo? Privado de tempo e de duração exigida pelos sentimentos, o indivíduo hipermoderno pode experimentar algo diferente de sensações? (Haroche, 2008, p. 123).
\end{abstract}

Em relação às sensações, tanto Haroche (2008) quanto Buck-Morss (2012) salientam a superestimulação da visão em relação aos demais sentidos. Se antes da mundialização capitalista predominavam a atenção e a reverência ao outro mediante a escuta (por exemplo, nas tradições orais) e o aprendizado manual de habilidades (como o artesanato), na era do capital o apelo visual passou a ser marca, o sentido dominante (Haroche, 2008). No entanto, não é a vista que se detém com atenção; é uma visão continuamente convocada a consumir estímulos. Paradoxalmente, assim subjuga-se o olhar, este aspecto da dimensão subjetiva que requer tempo de apreciação.

O impacto coletivo das mudanças verificou-se com mais veemência na segunda metade do século XIX, nas grandes cidades, conforme vários autores (Benjamin, 1995; Buck-Morss, 2012; Haroche, 2008). As duas últimas autoras reportam-se ao primeiro, em especial ao ensaio sobre Baudelaire (Benjamin, 1995, p. 124-125), no qual o filósofo comenta o impacto dos contínuos estímulos (ou choques) na consciência, no corpo e no comportamento humano:

Educação \& Realidade, Porto Alegre, v. 41, n. 2, p. 575-589, abr./jun. 2016. 
A Dimensão Estética na Aprendizagem

Entre os inúmeros gestos de comutar, inserir, acionar, etc., especialmente o 'click' do fotógrafo trouxe consigo muitas consequências. Uma pressão do dedo bastava para fixar um acontecimento por um tempo ilimitado. $\mathrm{O}$ aparelho como que aplicava ao instante um choque póstumo. Paralelamente às experiências ópticas desta espécie, surgiam outras táteis, como as ocasionadas pela folha de anúncio dos jornais, e mesmo pela circulação na cidade grande. O mover-se através do tráfego implicava uma série de choques e colisões para cada indivíduo [...]. Baudelaire fala do homem que mergulha na multidão como em um tanque de energia elétrica. E, logo depois, descrevendo a experiência do choque, ele chama esse homem de 'um caleidoscópio dotado de consciência'. Se, em Poe, os pedestres lançam olhares ainda aparentemente despropositados em todas as direções, os pedestres modernos são obrigados a fazê-lo para se orientar pelos sinais de trânsito. A técnica submeteu, assim, o sistema sensorial a um treinamento de natureza complexa (Benjamin, 1995, p. 124-125).

O que estaria ocorrendo na contemporaneidade é a habitualidade aos choques, uma vez que, no contexto das sociedades urbanas industrializadas, produzidas e produtoras de técnicas e grande fluxo de informações, o ser humano é estimulado continuamente. Buck-Morss (2012, p. 174) assinala que o sistema perceptual é neurologicamente afetado, haja vista que ocorre um entorpecimento dos sentidos. A este efeito a autora emprega o termo fantasmagoria e recorda que originalmente o vocábulo, na língua inglesa, foi utilizado na referência a uma exposição de lanternas, na Inglaterra, cujo atrativo era provocar alterações sensoriais. A propagação ampla de efeito semelhante e constante na coletividade não mais entretém o espectador por um momento curioso ou lúdico, e sim o retém, ilude na promessa de atrativos constantes e variados a serem consumidos. Todos precisam ser vistos, porém o olhar não pode se deter na apreciação, pois vários estímulos concorrem entre si. Pelo excesso/saturação, o consumidor é induzido a olhar (fisiologicamente), mas tem $o$ olhar ofuscado.

As fantasmagorias são uma tecnoestética. Surte o efeito de anestesiar o organismo, mas não pelo entorpecimento, mas pela inundação dos sentidos [...] e o que é mais significativo - seus efeitos são experimentados na coletividade [...] Todos vemos o mesmo mundo alterado e a fantasmagoria torna-se a norma social (Buck-Morss, 2012, p. 174).

Constitui-se, assim, uma estética de percepção considerada normal, uma estética que se funda muito mais nas experiências vividas (em alemão, Erlebnis) do que na experiência autêntica (Erfahung). Lima e Magalhães (2010) traduzem Erfahung como experiência autêntica e Erlebnis como a inautêntica, considerando que, para Benjamin, a primeira se caracteriza pelo enraizamento em referenciais sólidos na memória 
e na história de uma coletividade (cultura), ao passo que a vivência é da ordem do efêmero, logo recai no esquecimento, processo inevitável diante dos contínuos choques.

\begin{abstract}
Quanto maior é participação do fator choque em cada uma das impressões, tanto mais constante deve ser a presença do consciente no interesse em proteger contra os estímulos; quanto maior for o êxito com que ela operar, tanto menos essas impressões serão incorporadas à experiência, e tanto mais corresponderão ao conceito vivência (Benjamin, 1995, p. 111).
\end{abstract}

Este último conceito é significado pelo filósofo, na mesma obra, como experiência vivida em sentido restrito, como a do transeunte na multidão ou como a relação do operário com a máquina.

Na descrição desse contexto, depreende-se a constituição de um ser humano massificado e ofuscado, tanto pela multiplicidade de estímulos quanto pela velocidade das mudanças que exigem rápida e contínua adaptação/desadaptação e descarte. Não por acaso, pontua Haroche (2008), o homem das sociedades democráticas contemporâneas clama atenção à sua subjetividade, a despeito de toda a visibilidade que aparentemente lhe é conferida e proclamada como direito.

Concordamos que provavelmente nunca se falou tanto em atenção às individualidades, tanto politicamente quanto por meio de apelos pessoais (reivindicações e desejo de ser notado como especial). As minorias historicamente excluídas vêm se articulando com crescente expressão desde o século XX em movimentos sociais com vistas à conquista ou à igualdade de direitos.

A reivindicação de educação inclusiva aí se insere como defesa do direito de todas as pessoas - independentemente das diferenças de gênero, etnia, cultura, estrutura e dinâmica familiar, nível socioeconômico, condição de saúde, presença ou não de deficiência ou dificuldade de aprendizagem - frequentarem o mesmo sistema de ensino com garantia de acesso, permanência e qualidade. Não supõe adaptação da minoria, e sim adaptação do sistema educacional para a garantia desses direitos, à medida que este se compromete a atender às necessidades educacionais de todos mediante a oferta de recursos materiais - econômicos, técnicos, de adaptação ambiental - e humanos (capacitação docente, especialistas). Acordos internacionais foram firmados com esse propósito, tais como a Declaração Mundial sobre Educação para Todos (Unesco, 1990) e a Declaração de Salamanca, firmada em 1994, “[...] sobre Princípios, Políticas e Práticas na Área das Necessidades Educativas Especiais” (Unesco, 1994), e embasam políticas públicas de vários países.

Questionamos, entretanto, se o atendimento a essas necessidades, diretamente relacionadas aos déficits, implicaria reestruturação dos sistemas educacionais para além de adaptações funcionais, isto é,

Educação \& Realidade, Porto Alegre, v. 41, n. 2, p. 575-589, abr./jun. 2016. 579 
se demandaria ruptura com a predominante concepção de educar (por que se educa, para quê se aprende), que aparece atrelada às demandas do capital.

Como instituição eminentemente a serviço da preparação dos indivíduos para o exercício de competências consideradas importantes na (e à) sociedade, mediante acúmulo de determinados conhecimentos eleitos como fundamentais para tal, a escola contemporânea é constituída pela estética do choque e também a reproduz. A escolarização é posta como direito e necessidade social; é necessária ao mercado (formação para o trabalho) e ao consumo, razão pela qual estetiza-se na mesma lógica, ou seja, como preparatória, direcionada para determinadas habilidades, funções e objetivos a serem alcançados em curto prazo e sob competitividade. O provimento contínuo de conteúdos desprovido de um tempo necessário à reflexão, à compreensão e articulação de significados e à produção de sentidos pessoais e criatividade a partir do oferecido acarreta entorpecimento e esvaziamento: assim que o conteúdo é aplicado, ou seja, quando cumpre uma finalidade imediata, como a aprovação para a série seguinte ou um concurso, logo é descartado mnemonicamente, pelos sentidos e pela razão. Retomando nossa metáfora, primeiro a hipervisualidade a ser consumida; depois, as tintas ou imagens, sem serem estetizadas pela experiência autêntica, esvaem-se.

A discussão no campo educacional transcende, portanto, o atendimento às necessidades específicas de alguns ou o diagnóstico frequente de patologias de atenção e memória. Para além desses aspectos, importa discutir como a aprendizagem tem sido estetizada na relação com o saber e com o conhecimento. Nesse âmbito, a psicopedagogia oportuniza reflexões pertinentes.

\section{O Olhar Psicopedagógico na Relação com o Saber}

A psicopedagogia é um campo de atuação cuja origem, nas primeiras décadas do século XX, remonta à perspectiva de tratamento dos problemas de aprendizagem com base no modelo médico-pedagógico, ou seja, em reeducar o indivíduo considerado desviante dos padrões de comportamento e aprendizagem. O viés organicista foi acentuado na década 1970 e ainda norteia atuações (Ramos, 2007).

Nas últimas décadas do século XX a psicopedagogia tem redimensionado seus objetivos, seu objeto, bem como seus fundamentos e compromisso ético. Atualmente, afirma-se como campo de conhecimento - e não somente prático - orientado para a compreensão de como o sujeito aprende, no ambiente escolar ou fora dele, levando em consideração a influência de fatores orgânicos, emocionais, pedagógicos, sociais, culturais, entre outros (Ramos, 2007). Para tanto, convoca o entrelaçamento de conhecimentos diversos, notadamente o psicológico, o psicanalítico, o sociológico e o pedagógico. 
Na Argentina, onde a formação de psicopedagogo ocorre em nível de graduação há algumas décadas, a produção de teórica da área é mais abrangente e vem norteando a produção intelectual e cursos de pós-graduação no Brasil, inclusive em nível Stricto sensu. Como subsídio às reflexões do presente artigo, destacamos contribuições da psicopedagoga argentina Alicia Fernández, particularmente dois aspectos: a constituição do corpo na aprendizagem e como esta vem sendo socialmente fraturada, sobretudo no vínculo com o saber.

Segundo essa autora, “[...] a aprendizagem é uma construção singular que cada sujeito vai fazendo a partir de seu saber para ir transformando as informações em conhecimentos" (Fernández, 2001, p. 124). Cumpre explicitar a distinção entre informação e conhecimento. Na obra supracitada e em outra antecedente (Fernández, 1991), a autora afirma que o conhecimento não é transmitido em bloco; transmitem-se informações, signos, recortes, e é sempre algo do outro. Em espanhol diz-se enseña, cujo radical é o mesmo para insígnia e ensinar. Assim, a psicopedagoga cunha o termo ensinante para designar a posição de quem provê ensenãs. O aprendente, por sua vez, é aquele que potencialmente transformará as ensenãs em conhecimento, o que se dá por processos de objetivação (classificar, seriar, sistematizar) e de subjetivação (conexão com o próprio desejo de conhecer e de aprender a partir do que alguém oferta e também do que se deseja). O processo subjetivante tem a ver, ainda, com a conexão com o saber, e este se difere do conhecimento, como no seguinte exemplo:

O conhecimento é objetivável, transmissível de forma indireta ou impessoal; pode ser adquirido através de livros ou máquinas, é factível de sistematização em teorias; enuncia-se através de conceitos (O conhecimento tende a objetivar) em troca, o saber é transmissível só de modo direto, de pessoa para pessoa, experiencialmente; não se pode aprender através de um livro, nem de máquinas, não é sistematizável (não se encontram tratados de saber); só pode ser enunciado através de metáforas, paradigmas, situações, histórias clínicas.

O saber dá poder de uso, mas o conhecimento não. [...]

Pode-se entender por que em determinados sistemas é conveniente que circulem conhecimentos, mas não poder de uso sobre eles. [...]

Assim, se alguém diz 'Sei dirigir', supõe-se, caso tivesse um automóvel, que poderia sair dirigindo. Porém, se alguém diz 'Eu conheço como se dirige um carro', até o melhor amigo duvidaria de emprestar seu carro (Fernández, 2001, p. 63).

Ora, o que presenciamos (e vivenciamos) senão uma falta de conexão com o saber? A possibilidade de aprender retroalimentada pelo desejo que o processo proporciona (ou deveria fazê-lo) tem sido fraturada, não apenas por fatores diretamente relacionados a problemáticas 
A Dimensão Estética na Aprendizagem

pessoais (inconscientes, cognitivas, familiares, patológicas), mas, sobretudo, por uma dimensão sociocultural que supervaloriza o consumo e o imediatismo. Estar informado constituiu-se como valor competitivo; conhecimento também. Contudo, quando sua produção está vinculada a uma aplicabilidade imediata e com a promessa de resultados visíveis em curto prazo, maior o investimento e status. O processo de conhecer vem se transformando, portanto, em um ato de acelerada deglutição, em detrimento do saboreio, termo cuja raiz etimológica é a mesma de sabor e saber.

O saber, como assinala Bondía (2002), demanda algo cada vez mais raro em nossa época: tempo. Esse autor, reportando-se a Benjamin, também discorre sobre o desafio de resgatar a dimensão da experiência na educação, que é justamente a relacionada ao aprendizado de desfrutar, saborear. Correlacionando esta referência à leitura psicopedagógica, depreendemos ser imprescindível essa nutrição por parte do ensinante. Para Fernández (1991, 2001), só se aprende quando autorizamos o outro a nos ensinar e isso implica conexão com o desejo. E o que ocorre no mundo contemporâneo é que cada vez mais o outro (personificado no adulto, no professor, na família, na escola e em outras instituições) não se mostra ou pouco se mostra desejoso de que aprendamos movidos pelo sabor de aprender e sob a satisfação da continuidade que o processo alimentaria, sem preocupação imediata com os fins.

Parafraseando Freud, Fernández (2001, p. 107) comenta que o “mal-estar da civilização" atual, ao supervalorizar a técnica, as imagens dadas, a velocidade e o seu consumo, produz obstáculos e fracassos na potencialidade de pensar e mesmo “[...] quem pensa se sente excluído, já que o consumidor está deslocado no cidadão, e quanto menos pensam os consumidores, mais comprarão que é oferecido”. Nessa crítica, identificamos confluência com um já referido questionamento de Haroche (2008, p. 16, grifos da autora) sobre as possibilidades de estruturação de um sujeito neste contexto em que o ser humano é frequentemente “[...] conduzido à inatenção, ao estreitamento da consciência e à falta de simbolização dos sentimentos [...]", de tal modo que as individualidades reduzem-se à alienação nas sensações. Como exemplo, na mesma página, a filósofa menciona que "[...] o divertir-se passou a ser conjugado com o ensurdecer-se, e ambos temem se declinado pelo isolar-se”.

Em congruência - e então passamos ao segundo ponto da reflexão psicopedagógica - Fernández (2001) metaforiza a relação com o conhecimento a distúrbios alimentares e alerta que a somatização pode ocorrer, ou seja, estetiza-se no corpo algo que acontece nessa relação, pois trata-se de um modalidade de apre(e)nder. Assim compreende-se, por exemplo, o movimento de absorver e deglutir informações e conhecimentos, mas sem incorporá-los (torná-los corpo), de modo que, não por acaso, ocorre o esquecimento, a recusa ou a desatenção em relação aos conteúdos. No máximo o sujeito os devolve, à semelhança da bulimia, no cumprimento de uma função (passar de ano ou em uma prova). 
Novamente, assinala-se a desconexão das informações e/ou do conhecimento com o saber, ignorando-se que a vinculação - e, portanto, a aprendizagem - configura-se em um corpo e este é (re)construído pelo sujeito no processo. Resume Fernández (1991, p. 59):

Desde o princípio até o fim, a aprendizagem passa pelo corpo. Uma aprendizagem nova vai integrar a aprendizagem anterior; ainda quando aprendemos as equações de segundo grau, temos o corpo presente no tipo de numeração e não se inclui somente como ato, mas também como prazer; porque o prazer está no corpo, sua ressonância não pode deixar de ser corporal, porque sem signo corporal de prazer, este desaparece.

Em concordância com a filósofa e também psicopedagoga Sara Paín, Alícia Fernández salienta a distinção entre organismo e corpo:

Do ponto de vista do funcionamento, podemos tomar duas dimensões: a que pertence ao organismo, que é um funcionamento já codificado, e a do corpo, que é aprendida. $\mathrm{O}$ organismo necessita do corpo, como um gravador necessita de um instrumento de música original que emita o som para que ele possa gravar. [...]

Assim, quando uma pessoa canta, deve respirar de uma maneira particular: utiliza o organismo, mas seu canto está inserido no corpo. Pode-se dizer que canta com as cordas vocais, mas que não são as cordas vocais que can$\operatorname{tam}[\ldots]$

Não temos diálogo com organismo, mas temos diálogo com nosso corpo, nós o modulamos (Fernández, 1991, p. $58)$.

Pensando com os autores, a partir das reflexões que suscitam, entendemos que a aprendizagem guarda uma dimensão estética. Propositadamente empregamos o verbo guardar, pois em geral esta dimensão existe, mas não aparece; está em ponto cego, em consequência da estetização(?) da consciência e da percepção sob os choques contemporâneos. O contexto socioeducacional, econômico, histórico, político e midiático não favorece a valorização, a sedimentação nem a produção de experiências (as autênticas) ou de conhecimentos a elas vinculados. Empobrecido o solo do saber, mais empobrecidas as experiências e conhecimentos decorrentes, no que diz respeito à conexão com uma história e uma memória - pessoal e de uma cultura. Por conseguinte, ocorre a reprodução da efemeridade, da desorganização e da desatenção, somatizadas na anestesia dos sentidos (físicos) e na sensação de falta de sentido (objetivo e subjetivo) em relação àquilo que é posto para aprender.

Isso não significa, entretanto, a síntese de um raio-X pessimista. Justamente por identificarmos a dimensão estética da aprendizagem em ponto cego, acenamos possibilidades de desvendá-la, uma vez que o 
A Dimensão Estética na Aprendizagem

anuviamento não decorre de uma anomalia ou limitação fisiológica, e sim de como e do quanto nos movemos para superá-lo.

\section{Um Olhar Estético}

Nesse cenário que sinaliza para a miopia do pensamento em meio à sobreposição ofuscante de imagens, conteúdos, ruídos, informações e sob o grande olho da atenção global aos cidadãos, haveria lugar para o olhar sensível, aquele que depreende do vínculo com o saber, do saborear o conhecer, que requer tempo e apreciação? Considerando o exposto, sem dúvida ele se faz urgente e mesmo as somatizações - da recusa à insaciedade - sugerem que ele esteja aí clamado, desejado. Se compreendemos o olhar sensível como aquele endereçado à conexão com a subjetividade do outro, ampliamos o potencial de exercê-lo e de enxergar caminhos para tal. Com isso já nos movemos em relação ao ponto de cegueira, saindo da paralisação que imobiliza o pensar/agir/ sentir/conhecer/aprender.

O próprio Walter Benjamin não vaticinou o fim da possibilidade de experiência; ele identificou que ela já acontecia por meio da arte. Nos ensaios sobre Proust e Baudelaire (Benjamin, 1987; 1995), o filósofo enaltece as obras desses escritores justamente por expressarem a capacidade humana de transformar o fragmentado das vivências em algo memorável e estético.

Fernández (2001) também pontua a importância da arte como facilitadora da construção de imagens, de metáforas e do brincar, processo que favorece, assim, a (re)conexão inconsciente com o saber. Tanto a apreciação quanto a produção da arte potencializariam encontro com a capacidade criadora, denominado pela psicopedagoga de "momento estético". Nesses momentos, regidos pela sensibilização, o sujeito autorizaria-se a pensar e criar, constituindo-se, de fato, aprendente. Por isso, torna-se necessário "disseminar a ideia de pensar e entrelaçá-la com a experiência, a ação, a transformação. Pensar implica necessariamente transformar(-se). Quando digo 'Eu penso', estou construindo algo novo que não pensava antes" (Fernández, 2001, p. 106). Nessa perspectiva, a autora desconstrói o mito da contraposição: pensar versus agir. Pensar supõe ação, saída da imobilidade da queixa, da inércia do pensamento.

Movimentar-se, então, presume saída do automatismo para uma condução auto, de autoria e de autonomia, uma automobilidade com tomada de consciência, inclusive para retardar, retroceder ou cessar uma atitude; cessar certo movimento para conectar-se com outra possibilidade do próprio corpo e enxergar outro caminho. Nessa óptica, há que se ressaltar, como Bondía (2002), a relevância da passionalidade, não a que aliena, e sim a que permite o saboreio, a paixão, o experienciar; diríamos que é a atitude que permite a abertura do olhar sensível.

A existência da arte, sem dúvida, independente do seu uso terapêutico ou educacional, encarna um aprendizado a partir do sensível 
e ensina que é possível subverter uma estética massificadora. Todavia, tomá-la estritamente como disciplina para promover ou recuperar este aprendizado também é dirigir o movimento rumo a outro ponto cego, o do utilitarismo, que em geral canaliza respostas, como o didatismo das interpretações de texto. A experiência estética não precisa depender de objetos/elementos da arte para acontecer. Eles podem suscitar o olhar sensível, e em geral o fazem, mas o grande desafio é estender o horizonte deste olhar a contextos mais insípidos, menos férteis ao saboreio, de modo que aí se constituam sentidos de beleza no processo de aprender.

Belo, aqui, não se confunde com o ideal clássico apolíneo de perfeição da forma sob determinados critérios padrão. O sentido de beleza que apontamos tem a ver com a subjetividade, com a segurança da autoria, ainda que seja árduo o percurso. É mais evidente nas produções de escultores, compositores, pintores, atores, bailarinos ou escritores, pelas emoções que suscitam no espectador, mas também é assim nas ciências, mesmo nas mais exatas, na escultura da melhor forma/fórmula de aproximação. E pode ser assim na criatividade e na intencionalidade, no refletir, na apropriação e no uso de recursos técnicos, das informações e do conhecimento.

Lembremos que nas aprendizagens assistemáticas, à primeira vista tão simples que em geral nem requerem escola, o olhar sensível aparece como investimento afetivo à confiança, ao autoaprimoramento e à vontade de conhecer. É o que costumeiramente ocorre na primeira infância, no aprendizado de engatinhar, andar, falar, brincar... As etapas são comemoradas, os erros/tropeços são vistos como parte natural do desenvolvimento humano e o corpo estetiza gestos, movimentos e acordes nos vínculos com os primeiros ensinantes ou com os que aplaudem o aprendizado.

O belo, na infância, é justamente o potencial e o processo (movimento) de estar aprendendo, o lugar aprendente, em que é permitido e desejável descobrir, perguntar, explorar, mostrar-se como construção, e não como obra acabada. Esta última corresponderia ao adulto ou ao aluno que completa um ano escolar. Na escolarização e no contexto das regras da civilização, o sujeito precisa apresentar obras em determinado tempo e a partir do uso de predeterminadas matérias-primas para cumprir certos fins. Com isso, fecha os olhos à dimensão estética, àquela que requer tempo, prestar atenção, estender os olhos, tanto para produzir, quanto para espectar, apreciar, e então interrogar para o aprimoramento.

Nesta defesa do olhar sensível e do resgate da dimensão estética, não pretendemos ofuscar o logos e as exigências mais objetivas da cultura. Não se visa a uma fuga, muito ao contrário: se os defendemos, é para o enraizamento de um logos mais fecundo, que não recaia tanto à tentação viciosa de responder, mas permita-se retornar ao que lhe deu origem: à pergunta. Pode-se dizer que a pergunta é a infância do logos. Nesse sentido, concordamos com Kohan (2007, p. 245) na afirmativa de

Educação \& Realidade, Porto Alegre, v. 41, n. 2, p. 575-589, abr./jun. 2016. 585 
A Dimensão Estética na Aprendizagem

que "não há como abandonar a infância, não há um ser humano inteiramente adulto. A humanidade tem um sôma infantil que não lhe abandona e que ele não pode abandonar”. Esse autor reporta-se à concepção do filósofo Giorgio Agamben sobre infância, que não a situa em um plano cronológico nem em um lugar de inferioridade; ela é uma categoria de expressão do descontínuo, da irrupção do pensamento: "ela passa a ser a condição de rupturas, experiência de transformação e sentido das metamorfoses de qualquer ser humano, sem importar sua idade" (Kohan, 2007, p. 246).

Ao desocultarmos esse ponto, o da infância guardada (e latente como o olhar que transforma matérias em obras-primas), lembramos que não deve ser por acaso que em nossa cultura, na sabedoria popular, costuma-se dizer arteiro ou fazer arte na referência a crianças que agem/pensam/tramam, enfim, estetizam como ninguém espera.

\section{Considerações de um Olhar}

Trouxemos a metáfora do ponto cego para pensar a aprendizagem, sobretudo em uma dimensão mais subjetiva, considerando o contraste entre o propagado apelo de atender às necessidades educacionais de todos e as concretas condições para tal. Os desafios objetivos são muitos e complexos, das políticas públicas às adaptações arquitetônicas, técnicas e tecnológicas, incluindo a qualificação de pessoal e a distribuição demográfica de recursos humanos e materiais. Questiona-se, não sem razão, se o atendimento às necessidades específicas é possível dentro da presente estrutura político-educacional e sociocultural.

Constatando-se a persistência de dificuldades de aprendizagem, de fracasso escolar ou de queixas relacionadas à desatenção ao universo acadêmico, é questionável também se essa estrutura tem favorecido condições para a aprendizagem, mesmo quando os educandos são agrupados sob uma homogeneidade preestabelecida, ou seja, mesmo sem os especiais incluídos, e até quando as condições materiais são aparentemente favoráveis. Afinal, ainda que haja o provimento objetivo às necessidades visíveis, o não aprender ou então o aprender de superfície (aprender-esquecer), condizentes à estética vigente como normal, prevalecem: vigora a imediaticidade de consumir informações e reproduzir conhecimento.

Nesse panorama, pensar confluências entre a educação contemporânea e a abertura (ou o não fechamento) do olhar sensível é um desafio, mas, ao mesmo tempo, um vislumbre de mobilização do pensamento gerada justamente por uma sensibilização. Ela pode provir de experiências distintas da normalidade, no contato com anormalidades sensíveis que nos provocam espanto. Não por elas, mas pelo que não enxergamos; por não percebermos o belo no mais evidente, como no exemplo da observação de Antônio Cícero, referida no início deste artigo, em relação às folhas das árvores.

586 Educação \& Realidade, Porto Alegre, v. 41, n. 2, p. 575-589, abr./jun. 2016. 
As sutilezas de ver interrogam modos e modelos de ensinar e trazem o ensinante para a sua infância: o lugar de aprender. Põe-se em movimento, assim, a alteridade, o fazer junto na comunhão de experiências. Diríamos: o com-ver-junto.

As implicações desse mover para a subjetividade são nítidas, tanto para quem ensina quanto para quem aprende: concernem ao aprendizado com saboreio, experimentando. Assinalamos, porém, que as repercussões podem e devem ser mais abrangentes, se a pertinência do olhar sensível for convocada ao propósito de questionamento e modificação dos valores sociais dominantes. Nadja Hermann (2005, p. 70) avalia que a experiência estética traz "elementos novos para a crítica e melhoria de nosso agir moral”; por isso, ela é tão importante na educação, esta área que "sempre teve uma atração inevitável à unidade [...]", ou seja, a homogeneizar (Hermann, 2005, p. 72). Assim, como resume a autora, a estética;

[...] atua numa dupla dimensão: em primeiro lugar, contribui para desenvolver a sensibilidade para as diferenças de percepção ou de gosto, auxiliando na contextualização de princípios éticos com uma força que o cognitivo não consegue produzir; e, em segundo lugar, cria condições para o reconhecimento do outro, evitando os riscos da uniformização diante do universalismo (Hermann 2005, p. 72).

Dessa maneira, o resgate do olhar estético (sensível), que experimenta/experiência, implica também uma responsabilidade social, política e formativa, seja no presente momento e com a geração atual, como forma de resistência à massificação que anestesia, seja para com a formação das novas gerações, por instituir uma educabilidade pautada sob valores distintos dos predominantes. Essa perspectiva coadunaria-se com o propósito benjaminiano de, segundo Pereira (2009, p. 247), “[...] elaborar um projeto filosófico que fosse capaz de recuperar o verdadeiro sentido da experiência, de uma noção que pudesse se sobrepor àquela outra da sociabilidade burguesa, distanciada da tradição [...]”. O autor explicita que:

Benjamin busca, lato sensu, salvaguardar a possibilidade de um ser humano de se dar a experiências realmente significativas, a experiências que extrapolariam a capacidade de entendimento humano, que estariam para além daquilo que se poderia captar e dizer acerca do que acontece (Pereira, 2009, p. 252).

Se ainda nos identificamos em ponto cego com relação a captar o que (nos) acontece, vale lembrar que o primeiro passo para o desvendamento é justamente essa identificação. Nesse constatar, questionamos a possibilidade de caminhos alternativos ao pretensamente único, interrogamos possibilidades, e isso já reflete lucidez, pensamento crítico e perspectivas de um novo aprender. 
A Dimensão Estética na Aprendizagem

Recebido em 29 de junho de 2014 Aprovado em 23 de junho de 2015

\section{Notas}

1 Ponto cego: 1. Anat. Em cada retina, área por onde penetra nervo óptico, assim chamada por não existirem, no local, receptores sensoriais, não havendo, portanto, resposta à estimulação. 2. Num veículo automóvel, área que não se pode avistar por meio de retrovisores (Ferreira, 1999, p. 1605).

2 Em Bachelard, o termo espiritual não tem conotação religiosa ou metafísica; diz respeito ao intelecto, ao pensamento científico.

\section{Referências}

BACHELARD, Gaston. A Formação do Espírito Cientifico. Tradução: Estela dos Santos Abreu. São Paulo: Martins Fontes, 1998.

BENJAMIN, Walter. Obras Escolhidas I - Magia e Técnica, Arte e Política: ensaios sobre literatura e historia da cultura. Tradução: Sérgio Paulo Rouanet. 2. ed. São Paulo: Brasiliense, 1987.

BENJAMIN, Walter. Sobre Alguns Temas em Baudelaire. In: BENJAMIN, Walter. Obras Escolhidas III - Charles Baudelaire - um lírico no auge do capitalismo. São Paulo: Brasiliense, 1995. P. 103-150.

BONDÍA, Jorge Larrosa. Notas sobre a Experiência e o Saber de Experiência. Revista Brasileira de Educação, Rio de Janeiro, n. 19, p. 20-28, jan./abr. 2002.

BUCK-MORSS, Susan. Estética e Anestética: uma reconsideração de a obra de arte de Walter Benjamin. Tradução: Vera Ribeiro. In: CAPISTRANO, Tadeu (Org.). Benjamin e a Obra de Arte: técnica, imagem, percepção. Rio de Janeiro: Contraponto, 2012. P. 155-204.

FERNÁNDEZ, Alicia. A Inteligência Aprisionada. Tradução: Iara Rodrigues. Porto Alegre: Artes Médicas, 1991.

FERNÁNDEZ, Alicia. O Saber em Jogo: a psicopedagogia propiciando autorias de pensamentos. Tradução: Neusa Kern Hickel. Porto Alegre: Artmed, 2001.

FERREIRA, Aurélio Buarque de Holanda. Novo Aurélio Século XXI: o dicionário da língua portuguesa. Rio de Janeiro: Nova Fronteira, 1999.

HAROCHE, Claudine. A Condição do Sensível: formas e maneiras de sentir no Ocidente. Rio de Janeiro: Contra Capa, 2008.

HERMANN, Nadja. Ética, Estética e Educação: uma relação que ressurge. In: HERMANN, Nadja. Ética e Estética: a relação quase esquecida. Porto Alegre: EDIPUCRS, 2005. P. 69-75. (Coleção Filosofia-193).

JANELA da Alma. Documentário. Direção: João Jardim e Walter Carvalho. Brasil, $2001.73 \mathrm{~min}$.

KOHAN, Walter O. Infância: entre a educação e a filosofia. Belo Horizonte: Autêntica, 2007.

LIMA, Francisco Gudiene Gomes; MAGALHÃES, Suzana Marly da Costa. Modernidade e Declínio da Experiência em Walter Benjamin. Acta Scientiarum. Human and Social Sciences, Maringá, v. 32, n. 2, p. 147-155, 2010.

PEREIRA, Marcelo de Andrade. Juventude, Experiência e Conhecimento em Walter Benjamin: para um novo saber da educação. Currículo sem Fronteiras, v. 9, n. 2, p. 242-257, jul./dez. 2009.

588 Educação \& Realidade, Porto Alegre, v. 41, n. 2, p. 575-589, abr./jun. 2016. 
RAMOS, Géssica Priscila. Psicopedagogia: aparando arestas pela história. Vidya, Santa Maria, v. 27, n. 1, p. 9-20, jan./jun. 2007.

UNESCO. Declaração de Salamanca. Sobre Princípios, Políticas e Práticas na Área das Necessidades Educativas Especiais. Salamanca, 1994. Disponível em: $<$ http://portal.mec.gov.br/seesp/arquivos/pdf/salamanca.pdf >. Acesso em: 08 jul. 2013.

UNESCO. Declaração Mundial sobre Educação para Todos: satisfação das necessidades básicas de aprendizagem. Jomtien, 1990. Disponível em: <http:// unesdoc.unesco.org/images/0008/000862/086291por.pdf>. Acesso em: 08 jul. 2013.

Ana Beatriz Machado de Freitas é pedagoga, especialista em psicopedagogia, mestre em Psicologia e doutora em Educação (PUC Goiás).

E-mail: bianadefreitas@ig.com.br 